\title{
The Growth of the Axon Is Not Dependent upon Net Microtubule Assembly at Its Distal Tip
}

\author{
Wenqian Yu and Peter W. Baas \\ Department of Anatomy, University of Wisconsin Medical School, Madison, Wisconsin 53706
}

\begin{abstract}
Although there is agreement that the net addition of new microtubule polymer to the axon is required for its growth, controversy exists concerning the principal site in the neuron where this occurs. Some models hold that microtubule polymer is assembled within the cell body and translocated down the axon, while others hold that the net addition of polymer occurs at the distal tip of the axon. The foundation for the latter idea was a study in which anti-microtubule drugs were applied topically for $30 \mathrm{~min}$ to discrete regions of cultured sensory neurons (Bamburg et al., 1986). The axon continued to grow when the drugs were applied to the cell body, but stopped growing when the drugs were applied to the distal tip of the axon. Assuming that the sole action of the drug was to inhibit microtubule assembly, many workers have interpreted these findings as indicating that the growth of the axon requires net microtubule assembly at its distal tip. We repeated these experiments using a broader range of drug treatments, and evaluated using electron microscopy the effects of these treatments on microtubule levels. Our results indicate that the previous drug treatments went beyond inhibiting microtubule assembly, and also caused substantial microtubule disassembly. When the drug regime was altered so as to induce lower levels of microtubule disassembly in the distal region of the axon, the axon continued to grow. These results indicate that the growth of the axon is not dependent upon net microtubule assembly at its distal tip.
\end{abstract}

[Key words: neuron, axon, axon growth, microtubule, microtubule assembly, microtubule transport]

Axons contain dense arrays of microtubules that serve essential architectural and transport functions. There is widespread agreement that the addition of new microtubule polymer to the axon is critical for its growth. However, the manner by which this addition occurs has been a matter of disagreement in recent years. Some models hold that microtubules are assembled in the cell body of the neuron and then transported down the axon, while other models hold that the net addition of polymer occurs at the distal tip of the growing axon.

\footnotetext{
Received Mar. 17, 1995; revised June 14, 1995; accepted June 20, 1995.

This work was supported by grants from the National Institutes of Health and the National Science Foundation to P.W.B., who is also the recipient of a Research Career Development Award from the National Institutes of Health. We thank Drs. Robert Lustig and Richard Anderson for assistance, and several colleagues for helpful discussions. We especially thank Drs. James Bamburg and Dennis Bray for their kindness.

Correspondence should be addressed to Peter W. Baas, Department of Anatomy, University of Wisconsin Medical School, 1300 University Avenue, Madison, WI 53706.

Copyright (C) 1995 Society for Neuroscience $0270-6474 / 95 / 156827-07 \$ 05.00 / 0$
}

Microtubule transport was originally proposed in studies showing that tubulin moves down the axon unidirectionally, relatively coherently, at a steady rate, and in a form that persists under conditions that remove unassembled tubulin subunits (Black and Lasek, 1980; Brady and Lasek, 1982). Given that the only assembled form of tubulin that has been identified in the axon is the microtubule, these studies suggest that microtubules are actively transported down the axon. In support of this conclusion, studies from our laboratory suggest that microtubules destined for the axon originate at the centrosome within the cell body (Yu et al., 1993; Ahmad et al., 1994), and that these microtubules translocate into and down the axon even when new microtubule assembly is experimentally inhibited (Baas and Ahmad, 1993).

The distal assembly model is based principally on the results of a study reported by Bamburg and collaborators (1986) roughly a decade ago. This study used a novel approach to test whether the addition of new microtubule polymer underlying axon growth occurs principally within the cell body (consistent with micrntubule transport), or principally at the distal tip of the axon. The authors reasoned that inhibition of microtubule assembly at normally important sites should stop the axon from growing. They found that axon growth was abolished if anti-microtubule drugs were topically applied to the distal tip of the axon, but not if the same drug concentrations were applied to the cell body. The authors concluded that the distal tip of the axon is a major site of microtubule assembly necessary for the growth of the axon. Other workers have expanded upon this interpretation, and have concluded that the growth of the axon is dependent upon the net addition of microtubule polymer at its distal tip.

Implicit in these interpretations is the assumption that the sole action of the drugs was to inhibit microtubule assembly. However, no efforts were made to evaluate the actual effects of the drug treatments on the microtubulcs in the neuron. Given the fact that the Bamburg study has been used as the foundation for the distal assembly model, it is disturbing that so little is understood about the subcellular effects of the drug applications. For this reason, we felt that it would be important to repeat the study and explore the results in more detail. Toward this end, we used a broader range of drug treatments, and determined the effects of these treatments on microlubule levels using quantitative electron microscopy.

\section{Materials and Methods}

Cell culture. Dorsal root ganglia were dissected from $9 \mathrm{~d}$ chick embryos, treated with $0.25 \mathrm{mg} / \mathrm{ml}$ trypsin for $15 \mathrm{~min}$, and triturated with a Pasteur pipette into a single cell dispersion. The neurons were then plated onto "special dishes" that were prepared by adhering an acidwashed glass coverslip to the bottom of a $35 \mathrm{~mm}$ plastic petri dish into which had been drilled a $1 \mathrm{~cm}$ diameter hole (Whitlon and Baas, 1992). 

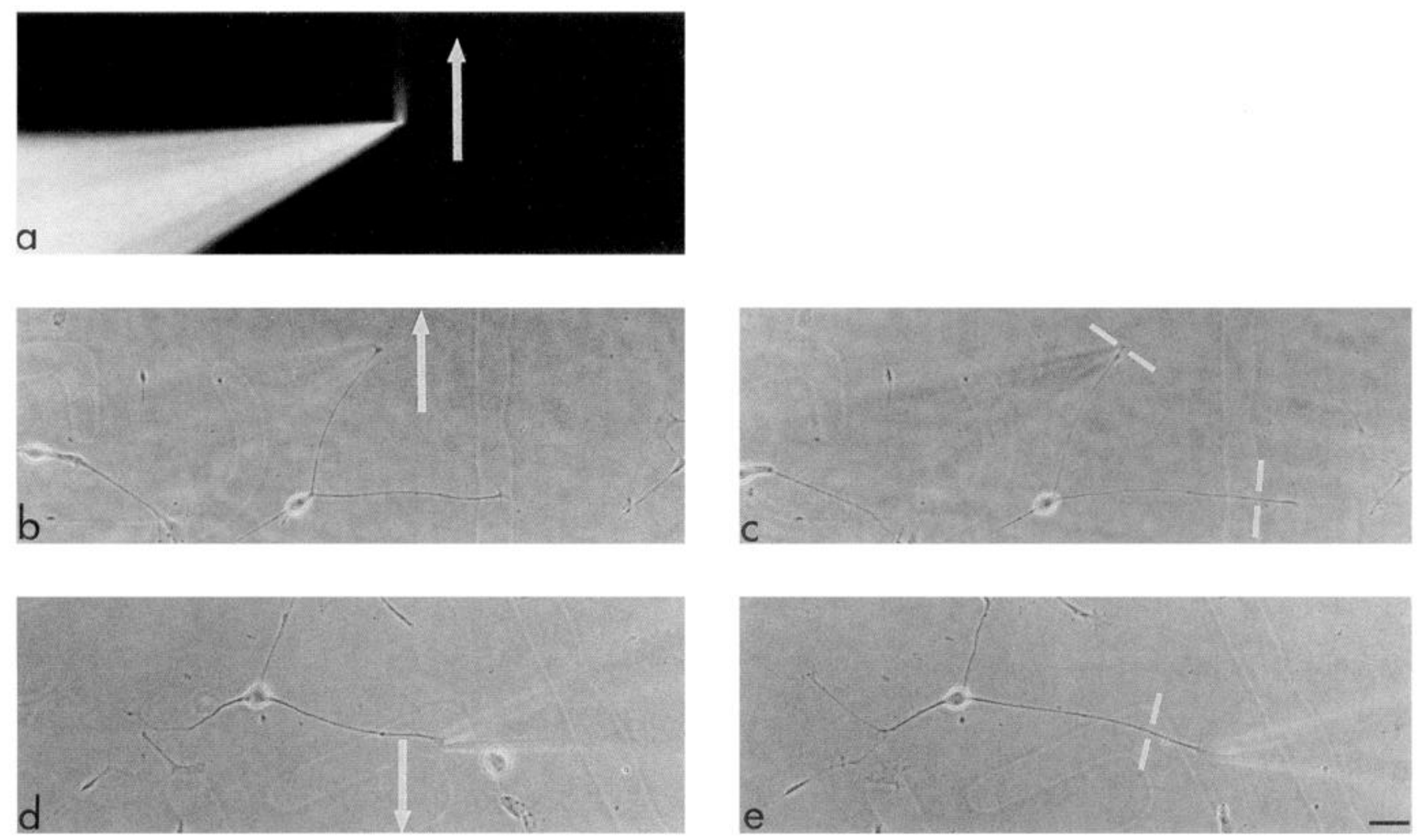

Figure 1. Effects on axon growth of drug applications at the distal tip of the axon. $a$ shows drug combined with fluorescein, carried away by a stream of medium. White arrows show direction of flow. $b$ and $c$ show 0 and 30 min respectively, as do $d$ and $e$. Control axons grew an average of over $25 \mu \mathrm{m}$, while application of $0.1 \mu \mathrm{g} / \mathrm{ml}$ nocodazole to the distal tip of the axon caused the axon to stop growing $(b$ and $c$ ). Application of $4 \mathrm{~nm}$ vinblastine did not cause axons to stop growing $(d$ and $e$ ). The length of the axon prior to drug treatment is indicated by white bars in $c$ and e. Scale bar, $24 \mu \mathrm{m}$.

To assist in relocating cells and in measuring axon growth, we used glass-coverslips into which a marked pattern had been photo-etched (Bellco, Vineland, NJ). Cells were plated in medium consisting of Leibovitz' L-15 (Sigma Chemical Company, St. Louis, IL) supplemented with $0.6 \%$ glucose, $2 \mathrm{mM}$ L-glutamine, $0.6 \%$ methyl cellulose, $100 \mathrm{U} / \mathrm{ml}$ penicillin, $100 \mu \mathrm{g} / \mathrm{ml}$ streptomycin, $10 \%$ fetal bovine serum (Hyclone, Logan, UT), and $100 \mu \mathrm{g} / \mathrm{ml}$ nerve growth factor. This medium maintains $\mathrm{pH}$ in normal air.

Experimental regime. The experimental regime was designed to duplicate as closely as possible that used by Bamburg et al. (1986). Cultures were placed on the stage of an Axiovert microscope (Carl Zeiss Inc., Thornwood, NY) equipped with an enclosed environmental chamber that maintains temperature at $37^{\circ} \mathrm{C}$. Plastic tubing was attached to opposite sides of the culture dish, and tissue culture medium was perfused across the dish using a peristoltic pump (see Bamburg et al., 1986). Drugs were dissolved in medium without methyl cellulose but containing $50 \mu \mathrm{g} / \mathrm{ml}$ fluorescein and $10 \%$ Ficoll, and applied to cells with a micropipette using the Eppendorf micromanipulator and microinjection system (Eppendorf, Hamburg). The flow of tissue culture medium carried the drug away before detectable levels could diffuse to other regions of the neuron. Drugs were applied for $30 \mathrm{~min}$, during which time the axons were photographed. Cultures were then fixed and prepared for electron microscopy. Nocodazole and colcemid were obtained from Aldrich Chemical Co. (Milwaukee, WI) and vinblastine sulfate was obtained from Sigma Chemical Company. Drugs were prepared, diluted, and used as previously described (Bamburg et al., 1986; Baas and Ahmad, 1992, 1993).

Electron microscopy. Fixation was performed by gently introducing into the culture an equal quantity of prewarmed medium containing $4 \%$ glutaraldehyde. After 20 min of fixation, the cultures were rinsed in 0.1 $\mathrm{M}$ cacodylate buffer, postfixed for $5 \mathrm{~min}$ in $1 \%$ osmium tetroxide, rinsed twice for $2 \mathrm{~min}$ in $\mathrm{NaCl}$, rinsed twice for $2 \mathrm{~min}$ in water, contrasted for $30 \mathrm{~min}$ in 5\% aqueous uranyl acetate, dehydrated in ethanols, and embedded in LX-112 (Ladd, Burlington, VT). After curing overnight at $60^{\circ} \mathrm{C}$, the cells of interest were relocated and the glass coverslip on which the cells had been grown was dissolved from the resin by exposure to hydrofluoric acid. Thin sections with a uniform thickness of $100 \mathrm{~nm}$ were obtained with an Ultracut S Ultramicrotome (ReichertJung, Vienna), picked-up on Formvar-coated slot grids, stained with uranyl acetate and lead citrate, and observed with a CX100 electron microscope (JEOL USA, Inc., Peabody, MA). For each experimental condition, microtubule levels were quantified in the middle longitudinal thin section taken from each of three samples. Statistical analyses were performed using the Student's $t$ test.

\section{Results}

Neurons were observed roughly $18 \mathrm{hr}$ after plating, by which time most had grown multiple axons that were typically 50-150 $\mu \mathrm{m}$ in length. For comparative purposes, we selected for our experiments axons of similar length $(\approx 85 \mu \mathrm{m})$ and width $(\approx 0.15 \mu \mathrm{m})$. As in the original study by Bamburg et al. (1986), anti-microtubule drugs were combined with fluorescein so that they could be visualized, and were topically applied with a micropipet to either the axon tip or the cell body. The drug was applied in the presence of a moving stream of culture medium which carried the drug away before detectable levels could diffuse to other regions of the neuron (see Fig. 1a). Three samples were analyzed for each experimental condition.

Drug applications at the distal tip of the axon. During the 30 min time frame of the experiment, control axons grew an average of over $25 \mu \mathrm{m}$ in length (see Fig. $1 \mathrm{~b} / \mathrm{c}$; Table 1). There was no significant difference between axons to which we had applied fluorescein with no drug and axons to which no topical applications were made. The former grew $25.4 \pm 2.2 \mu \mathrm{m}$ (see Table 1), while the latter grew $27.2 \pm 5.4 \mu \mathrm{m}$ (see Fig. $1 b / c$; 
Table 1. Effects on axon growth of drug applications at the axon tip: quantitative data

\begin{tabular}{llcc} 
& \multicolumn{2}{l}{ Length of axon $(\mu \mathrm{m})$} & Axon growth \\
\cline { 2 - 3 } & $0 \mathrm{~min}$ & $30 \mathrm{~min}$ & $(\mu \mathrm{m})$ \\
\hline Control 1 & $83.5 \pm 5.8$ & $108.9 \pm 8.09$ & $25.4 \pm 2.2$ \\
Control 2 & $79.8 \pm 14.9$ & $107.4 \pm 20.3$ & $27.2 \pm 5.4$ \\
Nocodazole, $0.1 \mu \mathrm{g} / \mathrm{ml}$ & $85.9 \pm 12.2$ & $85.9 \pm 12.2$ & 0 \\
Vinblastine, $4 \mathrm{nM}$ & $87.5 \pm 6.4$ & $101.4 \pm 11.0$ & $13.9 \pm 4.6$ \\
\hline
\end{tabular}

Shown are the lengths in micrometers of the axon at $0 \mathrm{~min}$ and $30 \mathrm{~min}$ (mean $\pm \mathrm{SD}$ ). $N=3$ for each condition. Control 1 axons were treated with fluorescein but no drug. Control 2 axons were not treated.

Table 1). As in the original study, application of $0.1 \mu \mathrm{g} / \mathrm{ml} \mathrm{no-}$ codazole or colcemid to the distal tip of the axon caused the axon to stop growing (see Fig. $1 b / c$; Table 1). Very different results were obtained when nanomolar levels of vinblastine sulfate were applied to the axon tip. At appropriate concentrations in the nanomolar range, vinblastine has been shown to suppress microtubule assembly while not causing substantial microtubule disassembly in previous studies on nonneuronal (for review, see Wilson and Jordan, 1994) and neuronal cells (Baas and Ahmad, 1993; Zheng et al., 1994; Ahmad and Baas, 1995; Tanaka et al., 1995). The precise concentration of vinblastine needed to achieve this effect varies under different experimental conditions and with different types of neurons, and for this reason we initially tried concentrations ranging from 2-32 nM. All concentrations of the drug diminished the extent of axon outgrowth. In most but not all cases, concentrations of $8 \mathrm{~nm}$ and greater stopped axon growth. $\Lambda 4 \mathrm{nM}$ concentration was the highest that permitted axon outgrowth in all cases, and for this reason we focused our attention on this concentration of the drug. In the presence of $4 \mathrm{nM}$ vinblastine, axons grew $13.9 \pm 4.6 \mathrm{~mm}$ during the $30 \mathrm{~min}$ time frame (Fig. $1 d / e$, Table 1). The growth of these axons was diminished by $46 \%$ relative to controls $(p<0.005)$.

Quantitative electron microscopy was performed on the nocodazole and vinblastine treatments, as results with colcemid were generally similar to those with nocodazole. Microtubule levels in electron micrographs were quantified in the middle longitudinal thin section taken from the axon. Axons were subdivided into four regions of equal length (labeled A-D from proximal to distal) that comprised the original length of the axon, and a fifth region (labeled E) that comprised any growth that occurred during the 30 min time frame of the experiment. Sample electron micrographs from the distal regions of control and experimental axons are shown in Figure 2. Data are presented in Table 2. Axons treated with $0.1 \mu \mathrm{g} / \mathrm{ml}$ nocodazole contained normal microtubule levels in regions $A$ and $B$ (no significant difference compared with controls). In addition to lacking a region $\mathrm{E}$, these axons showed reductions in microtubule levels of over $60 \%$ and $90 \%$ in regions $\mathrm{C}$ and $\mathrm{D}$, respectively $(p<$ $0.0005)$. Compared to the levels in a typical axon of the same length prior to drug application, there was a total reduction of over $40 \%$ ( $p<0.0005$ ). Compared to the levels of polymer in control axons after 30 minutes of additional growth, there was a reduction of over $60 \%(p<0.0005)$. These results indicate that the drug treatments used in the original study went far beyond suppressing microtubule assembly, and caused substantial microtubule disassembly.

Vinblastine treatment of the axon tip had very different effects on microtubule levels. Regions $\mathrm{A}-\mathrm{C}$ were similar to controls, while regions $\mathrm{D}$ and $\mathrm{E}$ showed reductions in microtubule levels of $\approx 40 \%$ and $\approx 10 \%$ compared to controls $(p<0.0005)$. In combination, regions $\mathrm{D}$ and $\mathrm{E}$ contained $\approx 30 \%$ less polymer than the original region $\mathrm{D}$ prior to drug application in corresponding control axons $(p<0.0005)$. Thus, the vinblastine treatment actually induced low levels of microtubule disassembly in the distal region of the axon, and yet did not halt axon growth. These results indicate that the growth of the axon is not dependent upon net microtubule assembly at its distal tip.

Drug applications at the cell body. As in the original study, the same drug concentrations that halted axon growth when applied distally had no effect on axon growth when applied to the cell body (data not shown). Concentrations of nocodazole or colcemid of $15 \mu \mathrm{g} / \mathrm{ml}$ at the cell body were required to stop axon growth (Fig. 3). At these higher drug concentrations, there was some retraction at the axon tip similar to that which occurred when the lower drug concentrations were applied at the axon tip. Comparison of electron micrographs from several different regions of cell bodies treated with the $1.0 \mu \mathrm{g} / \mathrm{ml}$ nocodazole indicate reductions in microtubule mass of roughly $50 \%$ compared to control cell bodies. Entirely similar results were observed in the cell bodies treated with $15 \mu \mathrm{g} / \mathrm{ml}$ nocodazole (Fig. 4a,b shows control and drug-treated cell bodies). The only difference was observed at the distal tips of the processes. At the lower levels of drug applied to the cell body, the microtubule mass at the axon tip was indistinguishable from control axon tips (not shown). At the higher drug concentration, most of the microtubule mass in the distal tip of the axon had depolymerized (Fig. 4c). The simplest interpretation of these results is that a fraction of the drug (undetectable by the fluorescence technique) when used at this concentration was able to diffuse to the distal region of the axon and depolymerize a substantial portion of its microtubule polymer. Support for this interpretation derives from observations on the tips of neighboring axons, many of which either stopped growing or turned and grew in a direction away from the gradient of drug (not shown).

\section{Discussion}

Prior to the Bamburg article, it was broadly accepted that microtubule transport from the cell body supplies the new polymer required for axon growth. The Bamburg article was immediately cmbraced as the foundation for a new model in which the net addition of polymer occurs at the distal tip of the axon. However, logistical problems both with the model and the experimental paradigm were also immediately recognized. Within a month of the original article's publication, it was noted that topical drug applications at the axon tip are informative only if the drug inhibits microtubule assembly without substantially depolymerizing the existing microtubules (Solomon, 1986). If the drug substantially depolymerizes microtubules in the distal region of the axon, the logic breaks down in that the axon would stop growing regardless of how the microtubules normally arrive in 

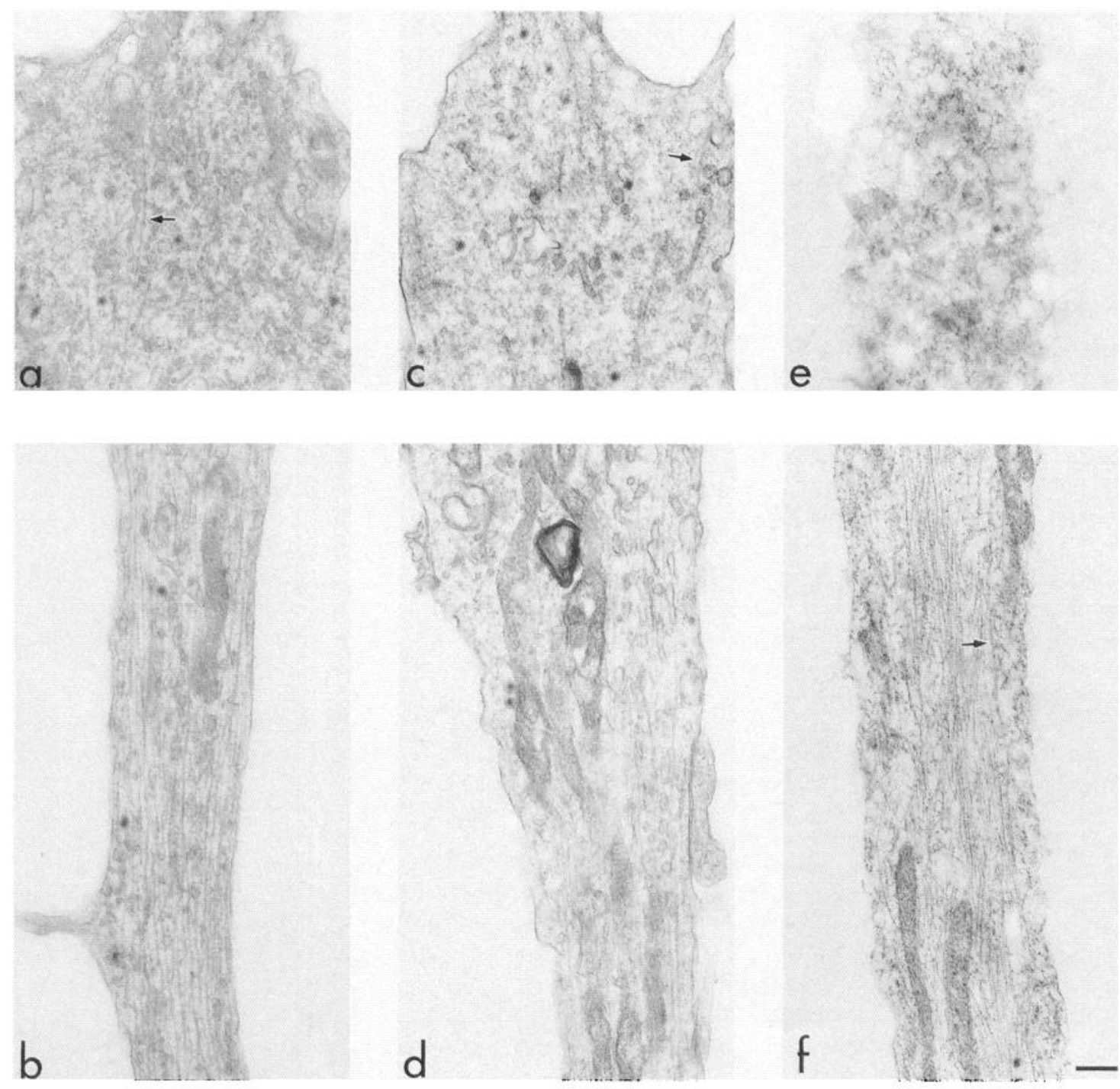

Figure 2. Effects on microtubule levels of drug applications at the axon tip. Shown are electron micrographs of the distal regions of axons whose distal tips had been exposed for $30 \mathrm{~min}$ to fluorescein alone (control, $a / b), 4 \mathrm{~nm}$ vinblastine $(c / d)$, or $0.1 \mu \mathrm{g} / \mathrm{ml}$ nocodazole $(e / f)$. The top tier shows the very tip of the axon, while the bottom tier shows a region within the most distal few microns of the axon. A dense array of microtubules is apparent in the distal region of the control axon, and these microtubules fan out into the axon tip. The vinblastine-treated axon also contains a dense array of microtubules, but polymer levels are somewhat lower than in controls. Only trace levels of microtubule polymer remain in the nocodazole-treated axon. Arrows point to microtubules. Quantitative data are shown in Table 2. Scale bar, $0.04 \mu \mathrm{m}$.

Table 2. Effects of microtubule levels of drug applications at the axon tip: quantitative data

\begin{tabular}{lcccc} 
& Control 1 & Control 2 & Vinblastine, $4 \mathrm{nM}$ & $\begin{array}{l}\text { Nocodazole, } 0.1 \\
\mu \mathrm{g} / \mathrm{ml}\end{array}$ \\
\hline $\mathrm{A}$ & $263.1 \pm 17.2$ & $238.2 \pm 79.1$ & $216.9 \pm 20.2$ & $224.8 \pm 36.7$ \\
$\mathrm{~B}$ & $234.1 \pm 5.3$ & $228.6 \pm 77.3$ & $200.2 \pm 26.5$ & $206.0 \pm 42.2$ \\
$\mathrm{C}$ & $221.5 \pm 22.3$ & $229.3 \pm 74.1$ & $193.7 \pm 24.2$ & $85.4 \pm 12.1$ \\
$\mathrm{D}$ & $230.1 \pm 21.1$ & $231.9 \pm 71.4$ & $144.8 \pm 13.8$ & $25.0 \pm 4.5$ \\
$\mathrm{E}$ & $269.1 \pm 58.0$ & $289.6 \pm 67.5$ & $23.2 \pm 4.2$ & - \\
$\mathrm{D}+\mathrm{E}$ & $499.2 \pm 79.8$ & $521.5 \pm 137.6$ & $154.4 \pm 25.5$ & $25.0 \pm 4.5$ \\
Total & $1217.8 \pm 122.2$ & $1217.5 \pm 362.2$ & $765.3 \pm 93.4$ & $541.2 \pm 100.1$
\end{tabular}

Microtubule levels were quantified (in micrometers) along the entire length of one thin section (middle section) for each of three axons under each experimental condition (mean \pm SD). Axons were subdivided into regions A-E as described in the Results. 

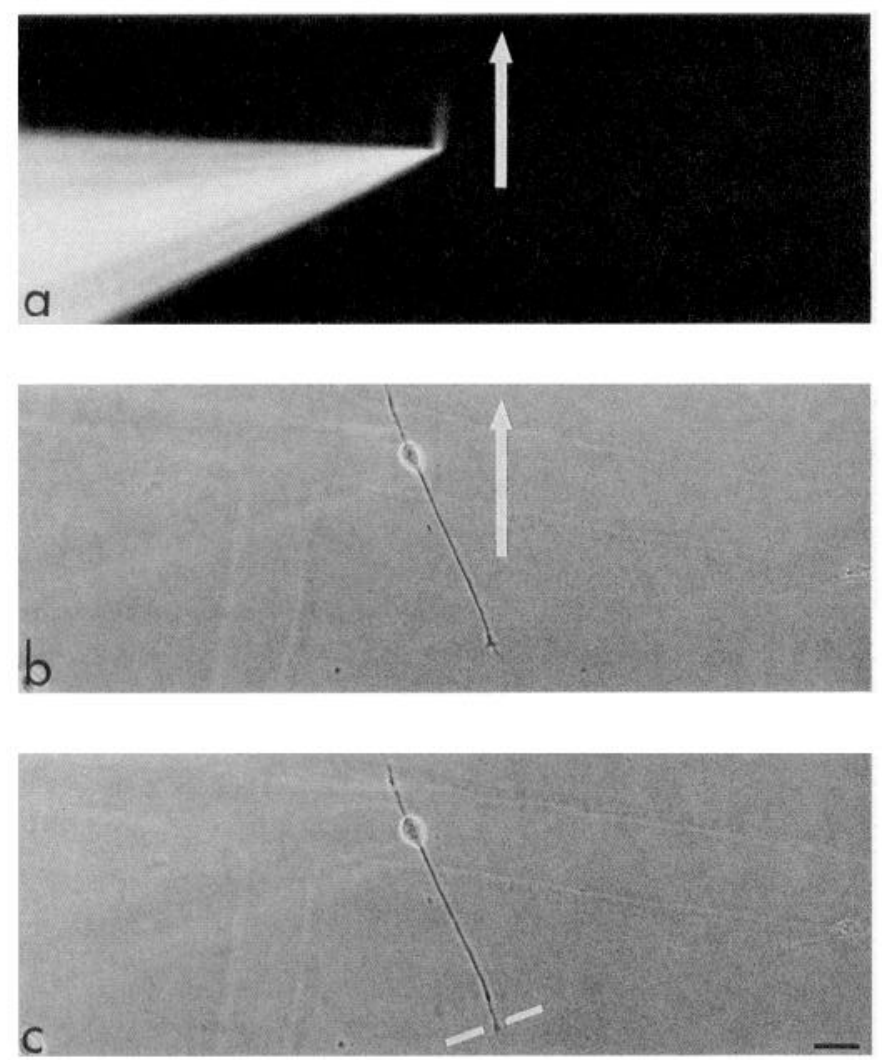

Figure 3. Effects on axon growth of drug application at the cell body. $a$ indicates direction of flow of medium (white arrow). Application to the cell body of nocodazole or colcemid at concentrations of 0.1 or 1.0 $\mu \mathrm{g} / \mathrm{ml}$ did not cause the axon to stop growing (not shown) Application of $15 \mu \mathrm{g} / \mathrm{ml}$ caused the axon to stop growing, and caused some retraction at the axon tip ( $b$ and $c$ ). The length of the axon prior to drug treatment is indicated by white bars. Scale bar, $24 \mu \mathrm{m}$.

this region. Our results indicate that the drug treatments used in the original study cause profound microtubule disassembly when applied to the distal tip of the axon, and are therefore not useful in resolving whether distal microtubule assembly is required for axon growth. Moreover, when we altered the drug treatment to produce substantially lower levels of microtubule disassembly, the axon continued to grow. These results contradict previous conclusions drawn from the Bamburg work and indicate that the growth of the axon is not dependent upon net microtubule assembly at its distal tip.

In interpreting our results, it is important to consider the effects of the vinblastine treatment on microtubule dynamics. Observations on the effects of vinblastine both in the test tube and in living cells indicate that nanomolar levels of the drug markedly reduce the frequency and extent of dynamic events (see Wilson and Jordan, 1994). At appropriate concentrations in this range, the drug also induces net disassembly of microtubules, and we have shown this to be the case under our experimental

Figure 4. Effects on microtubule levels of drug applications at the cell body. Application of $15 \mu \mathrm{g} / \mathrm{ml}$ nocodazole at the cell body decreased microtubule levels in the cell body by roughly half compared to controls ( $a$ and $b$ show control and drug-treated cell bodies respectively), and also caused substantial microtubule disassembly at the distal tip of the axon $(c)$. Scale bar, $0.03 \mu \mathrm{m}$.
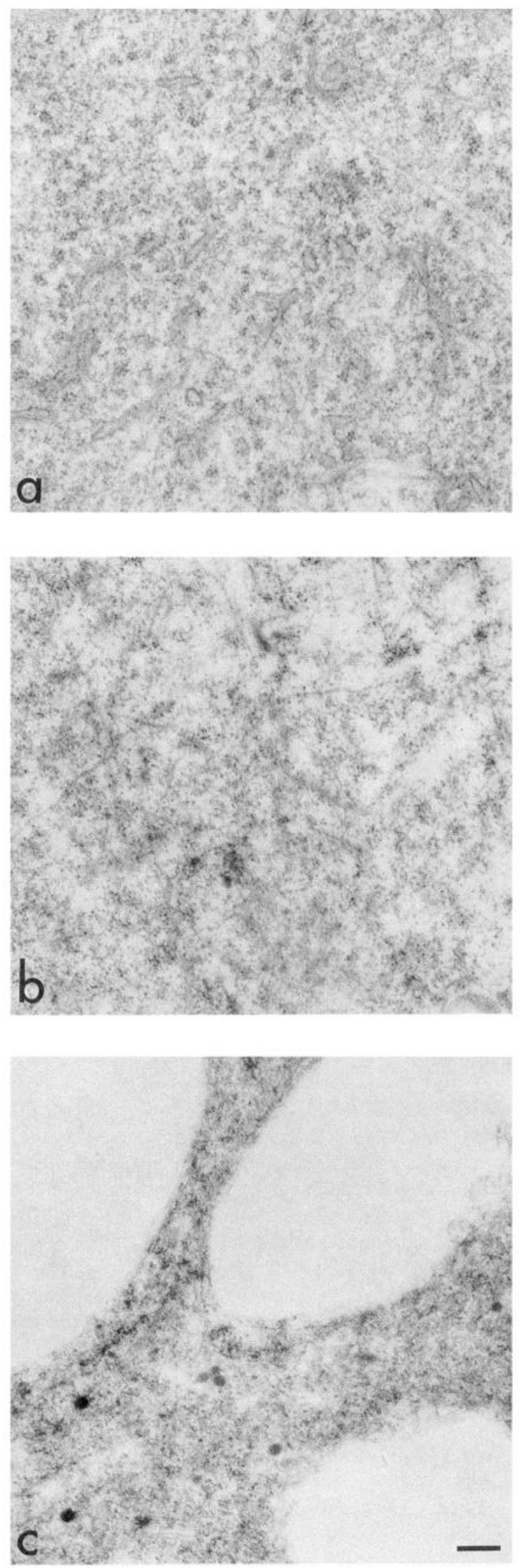
conditions. However, even under conditions that induce net disassembly, microtubules still undergo some subunit exchange at their ends. This is evidenced by their staining for tyrosinated tubulin (Baas and Ahmad, 1993) and by their incorporation of low levels of fluorescent tubulin microinjected into the cells (our unpublished observations). Thus, while our results indicate that net microtubule assembly at the distal tip of the axon is not required for its growth, we cannot dismiss the possibility that dynamic bouts of elongation of individual microtubules might play a role. Notably however, serial reconstruction and confocal microscopic analyses on cultured sympathetic neurons indicate that the same levels of vinblastine that induce low levels of disassembly also prevent individual microtubules from undergoing any substantial elongation (Baas and Ahmad, 1993; Ahmad and Baas, 1995).

We suspect that the reaction of the axon to vinblastine treatment varies under different experimental conditions and with different types of neurons. Tanaka et al. (1995) recently reported that vinblastine stops the growth of Xenopus axons when added to cultures over a similar time frame as our topical applications. In our studies, axon growth was diminished by about half compared to controls, but was not stopped. A likely possibility is that the degree to which axon growth is slowed relates directly to the degree of microtubule disassembly induced by the drug. It is noteworthy in this regard that we applied the drug topically to the axon tip, while Tanaka et al applied the drug to the medium. Another possibility is that microtubule dynamics influence axon growth in a way that is not related to a net increase in microtubule mass, perhaps for example by helping to regulate actin motility. Regardless, it is clear that axons can grow even when net microtubule assembly is curtailed and when microtubule dynamics are markedly dampened. In fact, we demonstrated in a previous study that axons grow, albeit slower compared to controls, over periods of several hours or even days in the presence of vinblastine concentrations manyfold those used here (Baas and Ahmad, 1993).

As we understand it, the topical drug applications to the cell body were undertaken in the original study to determine whether microtubule transport is required for the growth of the axon. It was assumed that microtubule transport in the axon is directly linked to microtubule assembly in the cell body, and hence that inhibiting the latter would stop the former. However, this assumption is mistaken in that microtubule assembly and microtubule transport are actually distinct events. A microtubule can move regardless of whether it is elongating, not undergoing a length change, or even shortening (see Baas and Ahmad, 1993). Thus, while it is true that inhibiting microtubule assembly within the cell body will ultimately deplete the neuron of microtubules that can be transported, this would not stop existing microtubules in the axon from moving over a time frame as short as thirty minutes. In addition, our data indicate that the microtubules in the cell body are more stable to drug-induced depolymerization than those within the distal region of the axon. It appears that the higher drug concentration when applied to the cell body stops axon growth not because it is more effective in depolymerizing microtubules in the cell body than the lower drug concentrations, but rather because a portion of the drug is able to diffuse to the axon tip and depolymerize its relatively more labile microtubule polymer.

Our results demonstrate that axon growth is not dependent upon the net addition of microtubule polymer at the distal tip of the axon. These results are inconsistent with a model for axon growth based on the net distal assembly of microtubules. In addition, there are other problems with such a model. The model essentially states that the net addition of microtubule polymer occurs via the assembly of tubulin subunits at the distal tip of the axon. However, it offers no explanation for how the subunits arrive in this region, and therefore cannot account for the fact that axons obtain lengths far greater than could be supported by diffusion of tubulin subunits. It is clear from the laws of physics as well as the kinetics of tubulin transport that tubulin must be actively transported down the axon (Lasek, 1986, 1988). There is no evidence supporting the idea that tubulin is transported as unassembled subunits, nor is there precedent for microtubulebased motors acting on soluble proteins rather than assembled structures. In addition, serial reconstruction studies on axonal microtubules indicate that microtubules undergo dynamic length changes all along the length of the axon, not just at its distal tip (Yu and Baas, 1994). Thus, while attractive on the surface, the distal assembly model is difficult to reconcile with physical laws and with available information on the axonal microtubule array.

Despite these problems, the historical importance of the Bamburg article should not be minimized. Until its publication, workers had focused principally on the cell body as the site where the axonal microtubule array is regulated. Even though these early workers recognized that microtubules in the axon are dynamic (Morris and Lasek, 1992, 1994; Brady et al., 1994), the Bamburg article was useful in bringing the issue to the fore. Subsequent work has shown that the microtubules extending into the distal region of the axon are particularly dynamic (Lim et al., 1989; Baas and Black, 1990; Brown et al., 1992; Ahmad et al., 1993; Baas et al., 1993), and that microtubule dynamics at the axon tip may be crucial for decision-making events such as the turning of the axon toward substrate or chemotactic factors (Tanaka et al., 1995; Bentley and O'Connor, 1994). However, we are unaware of any data that support the existence of net microtubule addition at the distal tip of the axon.

Concluding remarks. A great deal of work has been reported since the publication of the Bamburg article almost a decade ago. The issue of microtubule transport remains controversial due to the lack of consistent results provided by live-cell work (Keith, 1987; Lim et al,, 1989, 1990; Okabe and Hirokawa, 1989, 1992; Reinsch et al., 1991; Keith and Farmer, 1993). However, on the basis of several indirect lines of evidence, we have been persuaded to believe that the axonal microtubule array is elaborated via a combination of microtubule transport and assembly events (see Joshi and Baas, 1993). In our model, short microtubules are released from the centrosome and transported into and down the axon. As these microtubules move, they undergo dynamic length changes such that some microtubules elongate while others shorten. These length changes occur throughout the axon, and may certainly occur at its distal tip. However, it is important to note that unlike microtubule transport from the cell body, these shifts in microtubule lengths do not produce a net increase in the levels of polymer in the axon. Rather, they are important for transforming great numbers of short microtubules into smaller numbers of the longer microtubules that are characteristic of the axon. Thus, there is a division of labor in the axon, wherein both microtubule transport and local dynamics serve important but very different roles in the elaboration of the microtubule array.

\section{References}

Ahmad FJ, Pienkowski TP, Baas PW (1993) Regional differences in microtubule dynamics in the axon. J Neurosci 13:856-866. 
Ahmad FJ, Joshi HC, Centonze VE, Baas PW (1994) Inhibition of microtubule nucleation at the neuronal centrosome compromises axon growth. Neuron 12:271-280.

Ahmad FJ, Baas PW (1995) Microtubules released from the neuronal centrosome are transported into the axon. J Cell Sci, in press.

Baas PW, Black MM (1990) Individual microtubules in the axon consist of domains that differ in both composition and stability. $\mathbf{J}$ Cell Biol 111:495-509.

Baas PW, Joshi HC (1992) Gamma-tubulin distribution in the neuron: implications for the origins of neuritic microtubules. J Cell Biol 119: $171-178$

Baas PW, Ahmad FJ (1992) The plus ends of stable microtubules are the exclusive nucleating structures for microtubules in the axon. $J$ Cell Biol 116:1231-1241.

Baas PW, Ahmad FJ (1993) The transport properties of axonal microtubules establish their polarity orientation. J Cell Biol 120:14271437.

Baas PW, Ahmad FJ, Pienkowski TP, Brown A, Black, MM (1993) Sites of microtubule stabilization for the axon. J Neurosci 13:21772185.

Bamburg, JR, Bray D, Chapman, K (1986) Assembly of microtubules at the tip of growing axons. Nature 321:788-790.

Bentley D, O'Connor TP (1994) Cytoskeletal events in growth cone steering. Curr Opin Neurobiol 4:43-48.

Black MM, Lasek RJ (1980) Slow components of axonal transport: two cytoskeletal networks. J Cell Biol 86:616-623.

Brady ST, Lasek RJ (1982) Axonal transport: a cell biological method for studying proteins which associate with the cytoskeleton. Methods Cell Biol 25:365-398.

Brady ST, Tytell M, Lasek RJ (1984) Axonal transport and axonal tubulin: evidence for cold-stability. J Cell Biol 99:1716-1724.

Brown A, Slaughter TS, Black MM (1992) Newly assembled microtubules are concentrated in the proximal and distal regions of growing axons. J Cell Biol 119:867-882.

Joshi HC, Baas PW (1993) A new perspective on microtubules and axon growth. J Cell Biol 121:1191-1196.

Keith C (1987) Slow transport of tubulin in the neurites of differentiated PC12 cells. Science 235:337-339.

Keith C, Farmer M (1993) Microtubule behavior in PC12 neurites: variable results obtained with photobleach technology. Cell Motil Cytoskel 25:345-357.
Lasek RJ (1986) Polymer sliding in axons. J Cell Sci Suppl 5:161179.

Lasek RJ (1988) Studying the intrinsic determinants of neuronal form and function. In: Intrinsic determinants of neuronal form and function (Lasek RJ, Black MM, eds), pp 1-58. New York: Liss.

Lim S-S, Sammak PJ, Borisy GG (1989) Progressive and spatially differentiated stability of microtubules in developing neuronal cells. J Cell Biol 109:253-264.

Lim S-S, Edson KJ, Letourneau, PC, Borisy GG (1990) A test of microtubule translocation during neurite elongation. J Cell Biol 111: 123-130.

Morris JR, Lasek RJ (1982) Stable polymers of the axonal cytoskeleton: the axoplasmic ghost. J Cell Biol 92:192-198.

Morris JR, Lasek RJ (1984) Monomer-polymer equilibria in the axon: direct measurement of tubulin and actin as polymer and monomer in axoplasm. J Cell Biol 98:2064-2076.

Okabe S, Hirokawa, N (1989) Turnover of fluorescently labeled tubulin and actin in the axon. Nature 338:662-664.

Okabe S, Hirokawa, N (1992) Differential behavior of photoactivated microtubules in growing axons of mouse and frog neurons. J Cell Biol 117:365-380.

Reinsch SS, Mitchison TJ, Kirschner MW (1991) Microtubule polymer assembly and transport during axonal elongation. J Cell Biol 115 $365-380$.

Solomon F (1986) Microtubule assembly in the axon. Nature 322:599

Tanaka E, Ho T, Kirschner MW (1995) The role of microtubule dynamics in growth cone motility and axonal growth. J Cell Biol 128: 139-155.

Whitlon DS, Baas PW (1992) Improved methods for the use of glass coverslips in ccll culture and electron microscopy. J Histochem $\mathrm{Cy}-$ tochem 40:875-877.

Wilson L, Jordan MA (1994) Pharmacological probes of microtubule function. In: Microtubules (Hyams JS, Lloyd CW, eds), pp 59-84. New York: Wiley-Liss.

Yu W, Baas PW (1994) Changes in microtubule number and length during axon differentiation. J Neurosci 14:2818-2829.

Yu W, Centonze VE, Ahmad FJ, Baas PW (1993) Microtubule nucleation and release from the neuronal centrosome. J Cell Biol 122:349359.

Zheng J, Buxbaum RE, Heidemann SR (1994) Investigation of microtubule assembly and organization accompanying tension-induced neurite initiation. J Cell Sci 104:1239-1250. 